\title{
Aspectos da produção textual em planos de aula de língua inglesa do site Revista Nova Escola
}

\author{
Wanderleya Magna Alves" \\ José Cezinaldo Rocha Bessa**
}

\section{Resumo}

Nosso objetivo, neste trabalho, é identificar e analisar aspectos da produção de textos em propostas de planos de aula de língua inglesa do ensino fundamental disponibilizadas no site da Revista Nova Escola e discutir se e como esses aspectos podem contribuir para uma aprendizagem efetiva da produção textual como atividade de construção de sentidos. Como respaldo teórico, assumimos estudos que concebem a linguagem como instância política, dialógica e ideológica, bem como trabalhos que sustentam as potencialidades dos gêneros discursivos para o ensino. O corpus de análise se constitui de dois planos de aula de língua inglesa direcionados ao trabalho com o eixo escrita no ensino fundamental disponíveis no site da Revista Nova Escola. Nossa análise interpretativa do corpus recortado aponta que, embora os planos contemplem uma proposta de trabalho com textos, a atividade de orientação da produção textual ainda coloca muita ênfase na exploração do conteúdo temático, de determinadas características rígidas de tipologia textual e de aspectos gramaticais.

Palavras-chave: Planos de aula de língua inglesa; Aspectos da produção textual; Revista Nova Escola.
* Possui graduação em Letras/Língua Inglesa e respectivas literaturas, pela Universidade do Estado do Rio Grande do Norte (2007), Mestrado em Ensino, na área de concentração em Educação Básica, pela Universidade do Estado do Rio Grande do Norte (2019), Campus de Pau dos Ferros/RN. E doutoranda em Letras pelo Programa de Pós-Graduação em Letras, da Universidade do Estado do Rio Grande do Norte, situada na linha de pesquisa: Discurso, Memória e Identidade. É membro do Grupo de Estudos em Interação, Texto e Discurso do Alto Oeste Potiguar - GITED e do Grupo de Pesquisa em Produção e Ensino do Texto (GPET) e concentra interesse pelos estudos na área de Letras, com ênfase em Linguística, Linguística Aplicada, Língua Inglesa e Língua Portuguesa, dedicando-se especialmente a estudos informados pelas seguintes temáticas: gêneros do discurso, dialogismo e ideologia em perspectiva bakhtiniana, produção textual, leitura e escrita, ensino de língua inglesa e de língua materna. Atualmente, é Professora de Língua Inglesa na educação básica, lotada na Secretaria do Estado do Rio Grande do Norte. E-mail: wanderleyaalves@alu.uern.br

* Possui graduação em Letras/Língua Portuguesa e respectivas literaturas pela Universidade do Estado do Rio Grande do Norte (2005), mestrado em Estudos da Linguagem, na área de concentração em Linguística Aplicada, pela Universidade Federal do Rio Grande do Norte (2007), e doutorado em Linguística e Língua Portuguesa pela Universidade Estadual Paulista Júlio de Mesquita Filho, Campus de Araraquara, com período de estágio de doutorado no exterior na Université de Paris VIII (bolsa PDSE/CAPES). Atualmente é Professor Adjunto IV da Universidade do Estado do Rio Grande do Norte, no Campus de Pau dos Ferros, onde atua nos cursos de graduação em Letras e na pós-graduação. É docente permanente do Programa de Pós-Graduação em Ensino (PPGE/UERN), Mestrado Acadêmico, e docente permanente do Programa de Pós-Graduação em Letras da UERN (PPGL), Mestrado Acadêmico e doutorado. Como função administrativa, desempenha, em sua segunda gestão, a função de coordenador do Programa de Pós-Graduação em Ensino. É editor-chefe da revista Diálogo das Letras e membro do Conselho Editorial das Edições UERN. É líder do Grupo de Estudos em Interação, Texto e Discurso do Alto Oeste Potiguar - GITED e membro do Grupo de Pesquisa em Produção e Ensino do Texto (GPET) e do Grupo Slovo/UNESP. Concentra interesse pelos estudos na área de Letras, com ênfase em Linguística, Linguística Aplicada e Língua Portuguesa, dedicando-se especialmente a estudos informados pelas seguintes temáticas: gêneros do discurso, produção textual, leitura e escrita, ensino de língua materna, dialogismo, discurso citado, voz autoral, plágio, escrita e comunicação científica. E-mail: cezinaldobessauern@gmail.com

Data de submissão: dez. 2020 - Data de aceite: mar. 2021 http://dx.doi.org/10.5335/rdes.v17i01.11036 


\section{Introdução}

Este estudo parte do entendimento de que é no terreno do trabalho com os sentidos que o ensino de língua inglesa precisa fincar suas bases. $\mathrm{O}$ referido entendimento está relacionado a uma perspectiva de língua/linguagem como fenômeno sociocultural e ideológico, que leva em conta a situação em que as diversas formas de enunciados são produzidas, e, consequentemente, aspectos como: por quem os enunciados são produzidos, que ideologias os subjazem, como são ditos, para quem são dirigidos.

A defesa desse projeto, para a área do ensino de línguas, se faz ecoar na Base Nacional Comum Curricular (BNCC), que assume a pedagogia dos multiletramentos como perspectiva teórica norteadora de suas orientações para essa área. Tal pedagogia, consequentemente, passa a embasar, por exemplo, projetos pedagógicos, projetos de ensino, planos de aula e elaboração de livros didáticos, que são construídos levando em conta habilidades e competências destacadas nesse documento normativo (CURRY; REIS; ZENARDI, 2018).

Considerando que o site da Revista Nova Escola constitui uma fonte de interesse de grande número ${ }^{1}$ de internautas/ leitores/interlocutores e que tem se notabilizado por oferecer conteúdos, cursos, formações e planos de aula que sirvam de consulta/consumo por profissionais do ensino no Brasil, interessamo-nos por investigar um destes recursos didáticos, os planos de aula.

Nosso interesse pelos planos de aula, em particular, assume a compreensão de que, assim como ocorre com o livro didático, o uso desse tipo de material/ conteúdo pode se refletir em milhares de práticas de ensino espalhadas pelo Brasil, o que indica, portanto, a necessidade de submetermos esse tipo de material com propósito educativo, disponível na internet, a um exame crítico e reflexivo. A necessidade desse empreendimento investigativo fica mais evidente quando consideramos o número de seguidores do referido site e o número de professores que, segundo a Associação Nova Escola, acessam os planos. De acordo com informações do site Nova Escola, endereço https://novaescola.gupy.io/, existe, atualmente, cerca de três milhões de visitantes únicos por mês e, no que tange aos planos, esses materiais pedagógicos têm chegado a mais de $64 \%$ do professorado brasileiro, durante cada mês.

Como profissionais do ensino de línguas e pesquisadores interessados na investigação sobre aspectos que dão conta da relação entre universo digital e educação (BESSA; BERNARDINO, 2016; ALVES; BESSA, 2018; BESSA, 2019; BESSA, 2020), propomo-nos a examinar planos de aula relacionados ao componente curricular língua inglesa disponíveis no site da Revista Nova Escola focalizando, 
neste recorte, o trabalho com a produção de textos. Nesse sentido, o nosso objetivo é identificar e analisar aspectos da produção textual contemplados em propostas de planos de aula de língua inglesa do nono ano do ensino fundamental e discutir se e como esses aspectos podem contribuir para uma aprendizagem efetiva de produção textual como atividade de construção de sentidos.

É, portanto, com a intenção de contribuir com o debate crítico em torno do trabalho com a produção de textos no ensino de línguas, em particular, de língua inglesa, principalmente, tendo em vista este contexto de novas diretrizes para o ensino no Brasil, assim como do incremento das tecnologias digitais e dos múltiplos letramentos no processo de ensino e de aprendizagem, como defendem pesquisadores como Azari (2019), Dantas e Lima (2019) e Ribeiro (2020), que encontramos motivação para o desenvolvimento deste estudo.

\section{O ensino de produção textual em língua inglesa sob bases teóricas enunciativo-discursivas}

As transformações nos modos contemporâneos de se comunicar, bem como as diferentes perspectivas teóricas discursivas têm trazido para o campo do ensino de línguas variadas reflexões sobre o ensino do texto e da atividade de produção textual. (ZACHARIAS, 2016; GONÇALVES; TORRES, 2017). Nesse sentido, as capacidades e as habilidades requeridas das pessoas num mundo de textos constituídos de múltiplas semioses e complexos em sua organização e funcionamento têm colocado muitos desafios aos profissionais do ensino de línguas.

A escola, nessa perspectiva, parece andar muito lentamente. De acordo com Coscarelli (2016), mudanças são percebidas, no que se refere à adoção de uma perspectiva discursiva da linguagem. No entanto, tais mudanças ainda são tímidas, principalmente, no âmbito das práticas que exploram os gêneros característicos de ambientes digitais. Essa crítica mais pontual da autora chama mais atenção quando consideramos que o direcionamento discursivo dado ao ensino de línguas, inclusive na BNCC, apoiado na teoria dos multiletramentos e em postulados teóricos enunciativos, defende que os gêneros discursivos digitais e não digitais sejam tomados como objetos do ensino de línguas.

No que se refere ao ensino da produção textual, especificamente, o documento atenta para a importância de se trabalhar com a diversidade de gêneros discursivos. Cita, inclusive, aspectos que devem ser considerados no processo de produção (interlocutores, suporte no qual sairá veiculado, objetivos do texto), demonstrando o caráter discursivo no 
qual o documento assume se embasar. Ao atentar para a natureza processual e colaborativa da atividade de produzir, a BNCC (BRASIL, 2017) também a conceitua como prática social que pode favorecer a autonomia comunicativa do aluno.

A BNCC se ampara no que abordagens de base enunciativo-discursivas já vêm discutindo há algumas décadas: o trabalho com o texto em sala de aula não deve mais servir à memorização, à reprodução de textos, ou ser usado como pretexto para o ensino de gramática e vocabulário (SANTOS; COSTA, 2019; PAIVA, 2012). O entendimento construído é que esse tipo de atividade não é suficiente para atender a complexidade da demanda discursiva que o uso da linguagem engendra. A ênfase é na produção e na compreensão dos sentidos, porque o objetivo, nessa perspectiva, concentra-se na autonomia dos sujeitos alunos (ZOZZOLI, 2006; BRASIL, 2017).

Nesse contexto, o aluno deixa de ser concebido como um sujeito passivo, mas como um sujeito de resposta, com direito a voz; não de qualquer eco de voz, não de uma voz reproduzida apenas nos moldes do inglês comunicativo das décadas de 70 e 80, conforme criticam Cox e Peterson (2001), mas de uma voz construída nos diálogos que se dão nos mais diversos enunciados que constituem nossas experiências cotidianas, culturais e ideológicas como sujeitos de linguagem (SZUNDY, 2014).
Compreensões como as reportadas acima são atualmente compartilhadas por pesquisadores que têm como foco os textos como unidade de ensino, a maioria deles baseados na teoria de gêneros de Bakhtin (BEZERRA, 2017), mas pertencentes a bases teóricas distintas, como é o caso de estudiosos que se utilizam do Interacionismo Sociodiscursivo (ISD) de Bronckart (MACHADO, 2005; BEATO-CANATO; CRISTOVÃO, 2007; CAMPOS; CRISTOVÃO, 2007; CRISTOVÃO et al, 2010; PONTARA; CRISTOVÃO, 2017), a didática de gêneros do Grupo de Genebra (DOLZ, J.; NOVERRAZ, M.; SCHNEUWLY, 2004), bem como a teoria dos multiletramentos (The New London Group), que vem sendo constantemente associada aos usos e análises dos gêneros discursivos, aqui no Brasil, por Rojo e pesquisadores que tomam essa estudiosa como referência (ROJO, 2012; BARBOSA; ROJO, 2015) dentre outros.

$\mathrm{O}$ direcionamento epistemológico dessas abordagens está em formar os alunos para agirem como cidadãos e cidadãs críticos e reflexivos diante das ações discursivas que constituem a sociedade onde eles e elas vivem (SHERER; MOTTA-ROTH, 2015). Com relação a essa visão, Ribas (2018, p. 1790) permite-nos pensar que esse agir, na escola, deve ser pautado em questionamentos de verdades, deve provocar mudanças, "apresentando outras leituras de mundo, outros modos de interpretar a 
realidade". Assim, a compreensão ou produção de sentidos não pode ser uma atividade neutra, de significados dicionarizados. É preciso que se considere a constituição dos sujeitos, os seus espaços de constituição de subjetividades (MENDONÇA, 2019; ROCHA, 2009; PAIVA, 2012; CRISTOVÃO, 2010), e que sejam dadas oportunidades de convivência com leituras diversas e com atividades de produção textual que possam favorecer subsídios linguístico-discursivos capazes de agregar qualidade a essa aprendizagem (BESSA, 2019).

\section{Metodologia}

Nosso trabalho se situa na perspectiva de investigações em ciências humanas como concebidas por Bakhtin (2003), assumindo o pressuposto de que o "ser expressivo e falante" (BAKHTIN, 2003, p. 395) constitui o objeto de estudo de nossas pesquisas. Nessa perspectiva, corroboramos a posição de Amorim (2016, p. 21), para quem o texto é um "objeto que fala". Tal entendimento confere à pesquisa em ciências humanas uma dimensão interpretativa, mas não subjetiva (AMORIM, 2016), uma vez que a vontade de dizer de um sujeito é singular, individual, entretanto, tecida pelas vozes de outros sujeitos.

Com base na compreensão expressa no parágrafo anterior, o estudo desenvolvido assume uma abordagem qua- litativa, já que, em nosso exercício de pesquisa, pautamo-nos pelo cotejo de textos (BAKHTIN, 2016), que implica encontros entre consciências que dialogam, interpretam e atribuem sentidos (FARACO, 2009). Além disso, o estudo se caracteriza como uma pesquisa documental, uma vez que trabalhamos com dois planos de aula de língua inglesa do nono ano do ensino fundamental.

Os planos de aula ${ }^{2}$, corpus de nossa análise, encontram-se disponíveis no site da Revista Nova Escola. Eles foram construídos por professores selecionados pela Associação Revista Nova Escola, cuja mantenedora principal é a Fundação Lemann $(\mathrm{FL})^{3}$, uma das instituições que Macedo (2014) relata ter participação ativa nos debates sobre a BNCC.

Para os propósitos deste trabalho, selecionamos, para ilustrar nossa análise, dois planos de uma série de quinze que propõem a produção de dois gêneros discursivos diferentes: o primeiro se refere ao décimo plano da sequência, cuja proposta consiste na produção de um artigo de opinião; o segundo corresponde ao décimo quinto plano, que propõe a produção de uma fotorreportagem. O primeiro plano é nomeado, neste trabalho, como P10. Já o segundo é referenciado como P15.

Esses planos se encontram encaixados em um eixo temático, denominado de Eixo Escrita, e dentro de determinada unidade, neste caso, a unidade 
sete, na qual consta uma sequência de quinze planos. De acordo com a proposta da revista, todos esses planos são elaborados com base na BNCC, e, mais precisamente, baseados nas habilidades que a Base direciona para cada disciplina, encontrando-se constituídos das seguintes seções: "1. Sobre este plano"; "2. Objective"; "3. Context"; "4. "Input"; "5. "Output" e "6. "Feedback". Os planos ainda fornecem materiais extras, textos, atividades e chave de respostas.

Cumpre destacar ainda que os planos categorizados no eixo e unidade referidos tem como propósito a produção e compreensão de textos publicitários. $\mathrm{O}$ site tem alocado os planos, desde 2018, período em que vínhamos coletando materiais para a nossa dissertação de mestrado, porém não consta, na plataforma de acesso, nenhuma data de postagem.

Assumindo nosso exercício analítico, com base em pressupostos de abordagens enunciativo-discursivas da linguagem, esclarecemos que consideramos o enunciado em seu todo concreto, apesar de nos deter especialmente em algumas partes que podem nos ajudar a responder melhor os propósitos de nossa pesquisa. Nesse sentido, tudo que constitui nossos planos de aula importa; não somente os conteúdos que os constituem, uma vez que quem os fez, com que objetivos, como fez, para quem, baseados em que, entre outros questionamentos, podem nos ajudar a compreender de forma mais profunda certas escolhas teórico-metodológicas.

\section{Aspectos envolvidos na construção da produção textual em planos de aula de LI da Revista Nova Escola}

Esta análise parte da premissa de que as práticas sociais de linguagem se dão por meio de enunciados concretos que constituem sempre atos responsivos, historicamente situados e ideologicamente localizados (BAKHTIN, 2016). A defesa, que ora expomos, coaduna-se com pressupostos dos estudos da linguagem que levam em conta, além dos aspectos linguísticos, os aspectos discursivos (ROCHA, 2009). É nessa perspectiva que pretendemos analisar propostas de produção textual do componente língua inglesa presentes em planos de aula do site da Revista Nova Escola. Concentramo-nos especificamente em identificar e analisar aspectos da produção textual contemplados em propostas de planos de aula de língua inglesa do nono ano do ensino fundamental e discutir se e como esses aspectos podem contribuir para uma aprendizagem efetiva de produção textual como atividade de construção de sentidos.

Os planos de aula do site Nova Escola pertencentes ao Eixo Escrita da unidade 
sete foram planejados com vistas a uma progressão da atividade de produção textual, (começando do simples para o mais complexo), posto que a sistematização da proposta considera a realização de uma escrita fragmentada de determinados gêneros. Esse tipo de metodologia assemelha-se ao "princípio da aprendizagem aditiva" explicitado por Pasquier e Dolz (1996).

De acordo com os autores, essa abordagem compreende que a aprendizagem acontece do simples para o complexo, isto é, “considera-se que o todo é o resultado de uma soma de partes simples e que a transferência de um tipo de atividade a outra dá-se de maneira natural”. No caso do ensino de línguas, Pasquier e Dolz (1996, p. 5) acreditam ser "um duplo erro", uma vez que, para os autores:

[...] a atividade global e complexa, que determina os instrumentos específicos que $o$ aluno, induzido pelo ensino do professor, deve construir para chegar a resolver os problemas colocados por esta atividade. Não se trata, pois, de "compor" um texto a partir de elementos simples conhecidos, mas de "produzir" um texto como resposta a uma situação de comunicação complexa, recorrendo a múltiplos instrumentos e estratégias. (PASQUIER E DOLZ, 1996, p. 5).

Nossa leitura analítica permite perceber que a atividade de produção textual que, segundo a BNCC, deve ser concebida como "prática social", e, assim, oportunizar ao aluno "agir com protagonismo” (BRASIL, 2017, p. 242), adquire, nos planos que analisamos, uma sistemática que obedece a exercícios da estrutura textual e aspectos linguístico-gramaticais, somando-se a alguns questionamentos relacionados às temáticas que as propostas sugerem.

Passemos, então, para o exame do primeiro dos dois planos recortados. Para nos ajudar nesse exame, apresentamos, em um quadro a seguir, as principais seções do plano:

Quadro 1 - Plano de aula 10

\begin{tabular}{|c|c|c|c|}
\hline PROPOSTA - P10 & HABILIDADES DA BNCC & INPUT & OUTPUT \\
\hline $\begin{array}{l}\text { Estratégias de escrita } \\
\text { - construção da persu- } \\
\text { asão }\end{array}$ & $\begin{array}{l}\text { (EF09LI10) Propor potenciais argu- } \\
\text { mentos para expor e defender ponto } \\
\text { de vista em texto escrito, refletindo } \\
\text { sobre o tema proposto e pesquisan- } \\
\text { do dados, evidências e exemplos } \\
\text { para sustentar os argumentos, or- } \\
\text { ganizando-os em sequência lógica. }\end{array}$ & $\begin{array}{l}\text { Construir texto argu- } \\
\text { mentativo a partir de } \\
\text { elementos discursivos } \\
\text { e persuasivos, com } \\
\text { vistas à elaboração de } \\
\text { artigo de opinião. }\end{array}$ & $\begin{array}{l}\text { O output esperado ob- } \\
\text { jetiva que os alunos em } \\
\text { dupla consigam "agir } \\
\text { com protagonismo" } \\
\text { diante da produção de } \\
\text { um artigo de opinião. }\end{array}$ \\
\hline
\end{tabular}

Fonte: elaborado pelos autores

O referido plano visa à construção de argumentos para a elaboração de um artigo de opinião. Para dar conta desse objetivo, o plano está baseado na habilidade 10 da BNCC (2017, p. 263), do nono ano do Ensino Fundamental, que tem como objetivo "propor potenciais argumentos para expor e defender ponto 
de vista em texto escrito, refletindo sobre o tema proposto e pesquisando dados, evidências e exemplos para sustentar os argumentos, organizando-os em sequência lógica". O objetivo da proposta do P10, nessa mesma direção, tem como atividade "escrever a estrutura de um ensaio argumentativo baseado em argumentos persuasivos". Como visto, a habilidade base do plano busca focalizar elementos que tentam instrumentalizar o aluno para a tarefa de escrever, ao passo que a proposta de produção se torna uma espécie de avaliação do que foi apreendido em fases anteriores.

Em seu momento de contextualização e de input, este plano, assim como os demais da Revista Nova Escola, utiliza-se de uma temática, que é explorada por meio de alguns gêneros discursivos. Geralmente, dois textos servem como problematização para se constituírem tema das atividades de "produção textual". No caso dessa proposta, os textos são um vídeo da empresa alemã SAP (System Applications Products), que consiste de depoimentos de alunos e trainees sobre a atuação educacional desta empresa na promoção da formação de jovens para o mercado de trabalho, em países do continente africano, e um artigo de opinião de uma revista voltada para o público adolescente, que aborda questões relacionadas à pretensão juvenil quanto ao futuro.

A temática que envolve a proposta, na fase de contextualização, é abordada por meio de uma worksheet que procura explorar recursos imagéticos sobre o conteúdo que será apresentado no vídeo. Em contrapartida, na sequência, há questionamentos referentes a essa contextualização que nos parecem destoar da temática, uma vez que são indagações que exigem apenas relacionar questões de localização geográfica de países africanos:

Pergunte-lhes se o mapa do continente africano lhes é familiar e se eles saberiam localizar os países nomeados. Pergunte-lhes também se eles saberiam nomear e localizar algum outro país que não seja mencionado no slide [...] Pergunte-lhes: Este mapa é familiar para você? Você pode mostrar onde esses países estão localizados? Você é capaz de nomear e mostrar onde outros países africanos estão localizados?

Esta ocorrência nos remete a uma análise feita por Marcuschi (2008) acerca da natureza de atividades de compreensão em livros didáticos, em que, dentre alguns problemas levantados, estão os exercícios de compreensão que se desvirtuam da temática central e se direcionam por caminhos que "nada tem a ver com o texto ao qual se referem, mas serem apenas indagações genéricas ou de ordem subjetiva que podem ser respondidas com qualquer dado" (MARCUSCHI, 2008, p. 267). O autor, nesse sentido, critica também certos tipos de questionamentos de ordem superficial e de identificação, que não permitem a expansão ou construção de sentidos. 
Entendemos, ainda assim, que há uma certa preocupação com o aspecto do conteúdo temático, como pudemos constatar, inclusive, em outros planos da sequência dos quinze planos existentes na unidade. Para termos uma ideia, o plano $1\left(\mathrm{P} 1^{4}\right)$, por exemplo, busca discutir sobre os sonhos de adolescentes em relação ao futuro, ao mundo do trabalho e à vida pessoal. Para isso, nesse Plano 1 , atividades como mapas conceituais, vídeos e worksheets procuram explorar o tema a fim de que os alunos construam subsídios argumentativos para a atividade de produção.

Assim, após a exploração da worksheet, ainda na fase de contextualização, o P10 sugere apresentar o vídeo que trata da temática da aula: The future of employment. Entretanto, ao tentarmos assisti-lo, descobrimos que este não se encontra disponível ao público, cabendo, pois, ao professor selecionar um outro material ou mesmo recorrer a materiais do P1, uma vez que os planos orientam a adaptação das aulas neles propostas, a depender das diferentes realidades educacionais.
Na sequência, na fase de input, o plano apresenta um modelo de artigo de opinião para que o aluno tenha referência para começar a escrever o seu. Para isso, alguns questionamentos se remetem ao meio de circulação, aos autores e, novamente, ao conteúdo temático. "Onde esse artigo foi publicado?" "Qual é a principal característica desta publicação?" "Sobre o que, provavelmente, é este artigo?” O plano externa que em relação à essas perguntas, respectivamente, "é esperado que os alunos refiram à Teen Ink Magazine, e digam que os artigos são escritos por adolescentes [...]. É esperado que os alunos façam alusão a questões relacionadas à vida adulta, como casamento, filhos, trabalho, faculdade/universidade, etc". 
Figura 1 - Estrutura de um texto dissertativo

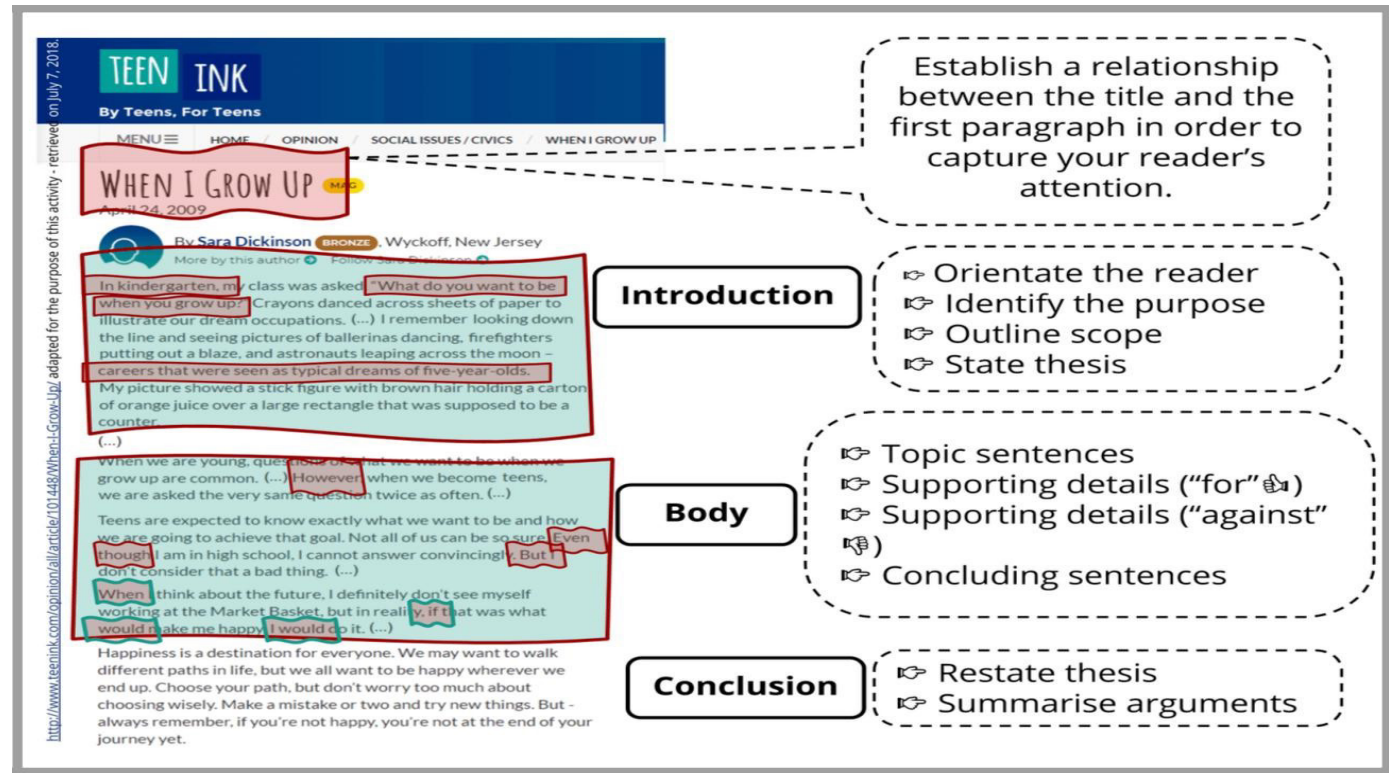

Fonte: Figura recortada do Plano de aula 10 - (Eixo escrita) da Revista Nova Escola

Segue-se a este arcabouço, orientações sobre como e o que se deve ser explorado, segundo o P10:

A partir desse momento, e ao primeiro clique, o título do artigo é destacado, seguido de uma "dica" sobre o título do artigo;

$>$ No segundo clique, os elementos de organização do primeiro parágrafo surgem com os respectivos exemplos;

$>$ No terceiro clique, os elementos de organização do parágrafo seguinte são apresentados, desta vez enfatizando conectores e orações condicionais. De qualquer forma, é recomendado que seja apontado aos alunos como os elementos discursivos estão presentes no parágrafo, procurando estabelecer relações através da utilização dos conectores: Look at these marks that we can see in this paragraph (however, even though, but)These are ways of connecting ideas. What kind of ideas do they connect?5[...] Na sequência, os elementos discursivos que marcam as orações condicionais são apresentadas. Assim, as relações contextuais do uso do zero conditional $^{6}$ e do second conditional ${ }^{7}$ são evidenciadas. [...].

$>$ Para explorar o uso das orações condicionais, ao quarto clique as palavras-chave que fazem referência às orações condicionais são highlighted e as relações contextuais podem, então, ser estabelecidas: These marked words state events that are related to the context. How do they relate? É esperado que os alunos estabeleçam relações com 0 tempo verbal, ou sejam conduzidos a isso. Respostas esperadas podem ser algo como WHEN refers to time and the verb THINK is in the present, ou algo como the word IF is followed by the modal WOULD in relation to MAKE and DO in the sentences...

Vemos aí que, apesar de enfatizar, em certo momento, a necessidade de apontar para o aluno a presença de elementos discursivos, as perguntas são direciona- 
das à função gramatical que os conectores e as orações condicionais exercem no texto modelo. O input, então, segue um percurso de perguntas que exigem, de acordo com as respostas esperadas, no trecho acima, certos tipos de identificação e função gramatical de palavras relacionadas ao conteúdo gramatical que pôde ser explorado no artigo-modelo.

Nesse sentido, pudemos perceber que a análise de aspectos gramaticais e da estrutura formal de parágrafos argumentativos constituem fortemente essa proposta, sendo o texto um meio para que essa tarefa se realize. Aqui, há, portanto, uma prática que muitos estudiosos têm criticado há muito: o uso do texto como pretexto para o exercício gramatical (PAIVA, 2012).

Adiante, nas conclusões, temos uma atitude diferente diante da análise do parágrafo e da orientação que se propõe, como podemos verificar no trecho explicitado:

$>$ Ao quinto clique, os balões que apresentam os aspectos estruturais da conclusão do texto surgem. Os alunos podem ser convidados a ler o parágrafo silenciosamente. [...]. A partir da leitura, será possível concluir que a tese e os argumentos da escritora são retomados. É importante que os alunos sejam advertidos quanto a isso. So, this is the point where the article is wrapped-up; the thesis is restated and the arguments are summarized. How do we do it? Neste momento, os alunos são convidados a elaborar suas respostas, referindo-se ao parágrafo final e propondo suas respostas, que poderão ser algo como the writer wants to be happy, ou the writer talks to her reader (s), ou the writer makes recommendations, etc.
Em relação à parte que compõe o texto-modelo, essa orientação segue com um questionamento que reflete sobre a percepção de como essa fase do artigo se constrói quanto ao tratamento de ideias e argumentos. Em nosso modo de ver, esse tipo de direcionamento pode ajudar o aluno a perceber características das fases do texto escolhido, e assim, também, passar a refletir nas suas futuras produções.

Após a análise do artigo-modelo, o P10, em sua fase de output, orienta a escrita do artigo focalizando questões que dizem respeito à circulação (Revista Teen Ink), ao endereçamento (leitores da revista), ao objetivo (o para quê escrever), além de preocupações como o tempo da escrita, tão caro para sua qualidade, uma vez que a produção textual não acontece de uma vez só, mas depende de um processo (ZOZZOLI, 2012).

Este momento da aula está configurado para ser trabalhado em duplas, com o apoio desta worksheet. A atividade em duplas é prevista como início da escritura do artigo de opinião, e poderá ser concluída individualmente, como tema de casa. Esta prática de produção escrita considera dois aspectos fundamentais: a natureza processual e colaborativa, além do objetivo do texto, sua circulação social e seus possíveis leitores, permitindo aos alunos agir com protagonismo. (PLANO DE AULA 10)

Somando-se às demais especificidades citadas e envolvidas na produção de um texto, o P10 encaminha a atividade de escrita do artigo para ser realizada de modo colaborativo. Contudo, propõe que 
a parceria entre os alunos seja restrita ao início da produção em sala de aula. Diante dessa proposta de atividade e da falta de justificativa para a não continuidade do trabalho em dupla, a natureza colaborativa destacada pelo Plano 10 parece não considerar a potência do processo de colaboração (ARAÚJO; FIGUEIREDO, 2015; SOARES, 2008) de maneira plenamente satisfatória.

Assumindo ancorar-se na BNCC e ressaltando aspectos que ela leva em conta em suas orientações, o Plano projeta, em sua fase de output que o aluno aja com protagonismo diante da escrita do artigo de opinião. É perceptível, dessa maneira, que ele considera alguns aspectos importantes para a efetivação desse protagonismo: oferece input e contextualização do tema tratado; concebe o texto como prática social, quando vislumbra sua circulação, interlocutores e objetivo de escrita; e ainda procura destacar aspectos linguístico-discursivos da estrutura textual.

É questionável, entretanto, algumas escolhas metodológicas e concepções nas quais o P10 se sustenta: questionamentos desvirtuados da temática proposta para exploração e a utilização do texto como pretexto para o ensino de certos grupos gramaticais. Diante dessas escolhas, o plano em análise deixa de evidenciar a importância de se refletir criticamente sobre as formas de dizer (GERALDI, 2017), tanto nas atividades de compreensão textual, na fase de contextualização, quanto nos momentos de análise da estrutura, na fase do input.

Uma vez focalizado o plano 10 , concentramos nossa atenção, nesse momento, na análise do plano 15 . O referido plano declara tomar como base as habilidades 12 e 16 do componente Língua Inglesa na BNCC (2017, p. 263):

(EF09LI12) Produzir textos (infográficos, fóruns de discussão online, fotorreportagens, campanhas publicitárias, memes, entre outros) sobre temas de interesse coletivo local ou global, que revelem posicionamento crítico.; (EF09LI16) Empregar, de modo inteligível, os verbos should, must, have to, may e might para indicar recomendação, necessidade ou obrigação, e/ou probabilidade.

Seu objetivo, nesse sentido, apresenta como objeto de escrita um gênero discursivo verbo-visual, uma fotorreportagem ${ }^{8}$. Assim, o plano baseado na habilidade 12 da BNCC intenta, de acordo com tradução ${ }^{9}$ nossa: "escrever fotorreportagens sobre nossas obrigações e necessidades como cidadãos para criar uma sociedade pacífica", conforme vemos sintetizado no quadro a seguir: 
Quadro 2 - Plano de aula 15

\begin{tabular}{|c|c|c|c|}
\hline PROPOSTA - P15 & HABILIDADES DA BNCC & INPUT & OUTPUT \\
\hline Práticas de escrita & $\begin{array}{l}\text { EF09LI12) Produzir textos (info- } \\
\text { gráficos, fóruns de discussão on- } \\
\text {-line, fotorreportagens, campa- } \\
\text { nhas publicitárias, memes, entre } \\
\text { outros) sobre temas de interesse } \\
\text { coletivo local ou global, que re- } \\
\text { velem posicionamento crítico. } \\
\text { (EF09LI16) Empregar, de modo } \\
\text { inteligível, os verbos should, } \\
\text { must, have to, may e might para } \\
\text { indicar recomendação, necessi- } \\
\text { dade ou obrigação, e probabili- } \\
\text { dade. }\end{array}$ & $\begin{array}{l}\text { Apresentar o tema da paz que ser- } \\
\text { virá de base para a atividade de } \\
\text { escrita proposta no output; } \\
\text { Assistir ao vídeo sobre a paz no } \\
\text { mundo para preparar a discussão } \\
\text { que servirá de base para a ativida- } \\
\text { de de escrita proposta no output; } \\
\text { Praticar as formas de must e have } \\
\text { to que servirão de base para a } \\
\text { atividade de escrita proposta no } \\
\text { output, focada em ações que pro- } \\
\text { movam uma sociedade pacífica. }\end{array}$ & $\begin{array}{l}\text { Elaborar fotorre- } \\
\text { portagens sobre } \\
\text { como as pessoas } \\
\text { deveriam agir para } \\
\text { promover a paz } \\
\text { no mundo usan- } \\
\text { do must/mustn't e } \\
\text { have to. }\end{array}$ \\
\hline
\end{tabular}

Fonte: Elaboração própria dos autores

Em sua fase de contexto, o P15 visa problematizar a temática $\mathrm{Paz}$ apresentando, primeiramente, um texto imagético em que se visualiza uma pomba e algumas palavras de sentido oposto ao símbolo. Para contextualizar o tema proposto, alguns questionamentos são apresentados: "existe algum problema com essa imagem?"; as palavras se referem a coisas positivas ou negativas? "Há um pássaro lá. Você consegue identificá-lo?" "Como você o chama?" "Por que eles (a imagem e as palavras de sentido oposto) não podem ficar juntos?" "Em sua opinião, o que pode contribuir para um mundo não pacífico?"

Nas fases de input, o plano dá continuidade as reflexões sobre o conteúdo temático. Nele, esta fase do input está dividida em três ocasiões: na primeira parte, o Plano trabalha com um texto verbo-visual que se refere à imagem captada de um vídeo cujo título, traduzido por nós, indaga: "Por que não existe paz no mundo?" (Why isn't there Peace in the World?)? A partir da imagem, que vem acompanhada de uma frase: "Todos queremos paz" (We all want peace"), inicia-se alguns questionamentos: "O que é paz para você?" (What is peace for you?); "Você acha que todo o mundo quer paz?" (Do you think the whole world wants peace?), "Ou apenas alguns países? Por quê/Por que não?" (Or just some countries? Why / why not?), "Por que você acha que os produtores fizeram um vídeo com esta pergunta?" (Why do you think the producers made a video with this question?), "Você concorda com eles?" (Do you agree with them?). Ademais, o plano orienta o professor a construir um mapa mental a partir das respostas dos estudantes.

As perguntas anteriores aludem ao conhecimento prévio dos estudantes e servem como uma preparação para a 
apresentação do vídeo. Este mostra diferentes formas de conflitos no mundo, bem como o agir conjunto e a meditação coletiva como forma de mudar a realidade, ou de olhar para esta realidade, para o próprio sofrimento e o das outras pessoas, de forma solidária. Assim, como em todos os textos, perguntas também são reportadas a seu respeito. A partir de uma imagem capturada, com os dizeres "Nosso mundo ainda está longe de ser pacífico" "Yet our world is far from peaceful"), a temática continua a ser explorada: "Você concorda com a captura da imagem?" (Do you agree with the caption in the image?) Por quê/Por que não? (Why/Why not?); "Você consegue pensar em algumas razões para a existência de conflitos no mundo?" (Can you think of some reasons for conflicts in the world?).

Os questionamentos referidos no parágrafo anterior norteiam a discussão trazida pelo vídeo, e, consequentemente, ajudam a embasar a atividade de produção de texto, uma vez que oferece ao aluno a oportunidade de refletir sobre o conteúdo temático do vídeo, e, possivelmente, pensar sobre sua própria produção. Essas possibilidades nos remetem às reflexões de Antunes (2003), que aponta uma inevitável interdependência entre leitura e produção de textos. Ainda que se refira a esta interpendência no âmbito da escrita científica, a posição de Bessa (2019) nos suscita a compreensão de que o repertório amplo e diversificado de leitura pode ajudar o aluno da educação básica a produzir textos com mais qualidade.

Além desses questionamentos, o plano sugere uma worksheet que visa a trabalhar com a compreensão sobre 0 vídeo. A atividade constitui-se de dois momentos: o primeiro momento requer do aluno a identificação de palavras que surgiram na projeção de parte do vídeo; já no segundo momento é apresentada uma sequência de cinco sentenças acerca do conteúdo temático do vídeo, em que o aluno precisa marcar apenas verdadeiro ou falso e corrigir o que ele considerar falso. Essa atividade, cumpre, em sua primeira parte, com o que o plano sugere a respeito do trabalho com o vocabulário do vídeo: "Read all the words and see if you don't understand any of them. (Caso haja dúvidas de vocabulário, escreva a palavra no quadro e peça a atenção de todos antes de explicá-la”. Quanto à segunda parte, resume-se, também, à identificação de algumas opiniões apresentadas no vídeo.

Nessa perspectiva, a worksheet não dá a possibilidade de expansão da discussão. A atividade de compreensão, nesse sentido, não mobiliza o aluno a uma compreensão ativa responsiva, aquela que, segundo Zozzoli (2012, p. 259), "implica uma tomada de posição ativa em relação ao que é dito e compreendido".

Em sua terceira fase, o input deste P15 se concentra na habilidade 16 do 
componente Língua Inglesa, do nono ano, que visa: "(EF09LI16) Empregar, de modo inteligível, os verbos should, must, have to, may e might para indicar recomendação, necessidade ou obrigação, e probabilidade". (BNCC, 2017, p. 263). O plano, então, se utiliza de uma worksheet que tem como foco o exercício descontextualizado dos verbos modais must e have to. A atividade requer apenas que esses modais sejam encaixados em períodos frasais que denotem necessidade e obrigação, respectivamente, sem qualquer menção à temática em questão. $\mathrm{O}$ exercício é proposto com a finalidade de, segundo o plano, "praticar as formas de must e have to que servirão de base para a atividade de escrita proposta no output."

Percebemos, mediante análise das duas primeiras fases de input que, assim como o P10, o P15 se preocupa com a discussão substancial da temática. Contudo, ao partir para a terceira fase, vemos que a habilidade 16 é posta em prática de forma desarticulada com a construção dos enunciados, como se costuma ressaltar em diversas pesquisas no contexto do ensino de Língua inglesa (ROTTAVA, 2004; FORTES, 2014; PONTARA; CRISTÓVÃO, 2017).

A fase de output, por sua vez, sugere como propósito: "elaborar fotorreportagens sobre como as pessoas deveriam agir para promover a paz no mundo, usando "must/mustn't e have to", e espera que isso seja possível "a partir do conhecimento prévio do aluno e das discussões em aula." Nesta fase, o plano ainda investe no conteúdo temático, oferecendo subsídio para a materialização discursiva da temática como, por exemplo, a reflexão por meio de fotografias encontradas no blog do projeto fotográfico "Humans of New York" (http:// www.humansofnewyork.com e http:// www.humansofnewyork.com/tagged/ iraq). Dessa maneira, no que tange ao conteúdo temático e aos materiais de suporte disponibilizados pelo plano, o seu propósito de "construir texto argumentativo a partir de elementos discursivos e persuasivos, com vistas à elaboração de artigo de opinião" tem possiblidade de ser alcançado.

Entretanto, apesar de sugerir a escrita de um gênero específico (a fotorreportagem), sua preocupação, em alguns momentos, parece ser a de saber se as formas dos verbos modais estão sendo utilizadas de acordo com a regra, conforme orientação dada: "Monitore o trabalho dos alunos, certificando-se de que estejam usando must e have to corretamente, bem como ajudando-os com dúvidas sobre vocabulário e pronúncia"; "Não esqueça de que você precisa usar 'must' ou 'mustn't' e 'have to' porque nós estamos falando sobre nossas necessidades e obrigações." (Don't forget you need to use 'must' or 'mustn't' and 'have to' because we're talking about our needs and obligations.). É evidente 
a importância que o P15 dá ao uso dos conteúdos gramaticais nessa proposta de produção, na medida em que, além dessa orientação e do input específico sobre verbos modais, a proposta expressa em seu propósito a obrigatoriedade do uso dos verbos estudados.

Percebemos, assim, que o propósito de usar os verbos se sobrepõe, em certa medida, ao objetivo que o plano expõe: "refletir sobre as obrigações e necessidades de cada cidadão que possibilitam uma sociedade mais pacífica." Vemos, com isso, que a proposta engessa o modo de dizer, o estilo do produtor, ao orientá-lo a usar apenas aqueles verbos modais para designar necessidades e obrigações dos cidadãos na busca por um mundo pacífico. Com efeito, esse limite imposto pela orientação se assemelha bastante ao que muitos estudiosos da área do ensino de línguas já observam há algum tempo: o uso do texto a favor do exercício gramatical (MENDONÇA, 2007; PONTARA; CRISTOVÃO, 2017).

Nesse sentido, considerando os insumos disponibilizados com vistas a se pensar na temática para problematizá-la, o investimento no aspecto conteúdo temático é o destaque positivo deste Plano, seguido de informações sobre o gênero proposto para a produção. Por outro lado, além do foco gramatical no trabalho de produção e diferentemente do plano anterior, a produção proposta pelo P15 fica restrita à sala de aula.
Um gênero que tem como característica narrar histórias, por meio de fotografias, combinando modos semióticos (AGOSTINETI, 2010) é orientado, na fase de output, à escrita de frases para serem corrigidas pelo professor e afixadas em murais: "à medida que os grupos forem terminando de escrever as frases, corrija as produções para que os alunos preparem as frases para expô-las pela escola". Diante desse direcionamento, podemos observar que aspectos como estilo, interlocutores, circulação social do gênero não ganham o destaque que toda proposta de produção, que se assume discursiva, deveria abranger (SZUNDY, 2014).

\section{Conclusão}

O propósito da discussão deste trabalho insere-se dentro da perspectiva de contribuir com as reflexões e pesquisas sobre o ensino e aprendizagem da produção textual em língua inglesa, considerando um contexto de disseminação de recursos educativos em plataformas digitais. Nesse sentido, tivemos como objetivos identificar e analisar aspectos da produção textual contemplados em propostas de planos de aula de língua inglesa do nono ano do ensino fundamental da Revista Nova Escola e discutir se e como esses aspectos podem contribuir para uma aprendizagem efetiva de produção textual como atividade de construção de sentidos. 
Para darmos conta desses objetivos, elegemos como corpus de pesquisa planos de aula de língua inglesa do nono ano do ensino fundamental disponibilizados no site da Revista Nova Escola. Nosso olhar interpretativo sobre o Eixo Escrita dos dois planos tomados para exame teve como respaldo teórico estudos que concebem a linguagem como instância política, dialógica e ideológica, assim como trabalhos que defendem as potencialidades dos gêneros discursivos para desenvolver habilidades necessárias para o uso efetivo da língua em estudo.

Nossas análises revelam que as atividades de produção propostas nos planos examinados intentam um trabalho com base na leitura e na produção de gêneros discursivos. Todavia, apesar de os dois planos se destacarem positivamente quanto à discussão das temáticas, outros aspectos merecem um tratamento mais cuidadoso. No P-10, por exemplo, a orientação da atividade de produção textual, em sua fase de input, se concentra exclusivamente no ensino de determinadas características rígidas da tipologia dissertativa (a tripartição: introdução, desenvolvimento e conclusão) com foco em conectores, em detrimento do destaque para as diferenças nos modos de dizer, nos estilos, por exemplo.

Percebemos, além disso, que a proposta do P10 procura se situar num contexto autêntico de interlocução, concebendo a produção textual como processo e direcionada a um objetivo. Por conseguinte, o P10 toma a produção como resposta a outros destinatários e com vistas a uma circulação social, aspectos que dão à proposta um caráter interativo, interlocutivo. De modo diferente, o $\mathrm{P} 15$ restringe sua proposta de produção a uma atividade típica e meramente escolar, uma vez que seu objetivo não ultrapassa o limite das paredes da escola. Ademais, esse plano concentra bastante empenho no conteúdo gramatical indicado para o uso na atividade de produção da fotorreportagem, motivo pelo qual nos faz perceber um certo pretexto para utilização da produção textual com vistas a se exercitar alguns verbos modais.

Diante desses resultados, percebemos que o valor sócio-histórico e político dos dizeres (ALVES; BESSA, 2018) necessita ainda de um pouco mais de atenção em propostas que têm como base o compromisso com uma formação cidadã, crítica e reflexiva. (RIBAS, 2018; DONATO; RAJAGOPALAN, 2017; ROCHA; MACIEL, 2015). Entretanto, reconhecendo já alguns avanços, reforçamos a necessidade de se pensar a atividade de produção textual como atividade interativa, que deve prescindir de uma atitude responsiva diante dos dizeres que se pretende (SZUNDY, 2014). Assim, levar em conta as condições de produção, os estilos dos autores e dos textos, interlocutores, conteúdo temático, estrutura composicional, 
circulação social, entre outros aspectos, são de fundamental importância para uma atividade de caráter complexo como a construção de sentidos dos enunciados.

Podemos observar, portanto, que, apesar de assumirem estar embasados num documento normativo que se orienta por pressupostos teórico-metodológicos de ensino de produção textual concebido como uma prática de construção de sentidos, as propostas dos planos analisadas ainda corroboram, no mais das vezes, práticas há muito tempo criticadas por estudiosos da linguagem, considerando que a ênfase recai, sobretudo, no texto como pretexto para exploração de aspectos temáticos e/ou de natureza gramatical.

Compreendemos, assim, que planos de aula como os analisados aqui, para serem utilizados em sala de aula, dentro da perspectiva teórico-metodológica que declaram assumir, supõem professores com capacidade de análise crítica, no sentido de poderem enxergar neles suas potencialidades e limitações e de adequá-los a cada realidade de sala de aula. O uso de tais planos, portanto, sem qualquer ação do professor numa perspectiva de incorporação de outros aspectos de natureza enunciativo-discursiva que caracterizam o funcionamento da linguagem como fenômeno sociocultural e ideológico resulta numa atividade com pouco potencial de desenvolver uma formação sociodiscursiva do aluno.

\section{Aspects of textual production in English language lesson plans from the Revista Nova Escola website}

\section{Abstract}

our objective, in this work, is to identify and analyze aspects of text production in proposals of English language lesson plans for elementary education made available on the website of Revista Nova Escola. It also consists in discussing whether and how these aspects can contribute to an effective learning of textual production as a meaning activity. As theoretical support, we assume studies that conceive language as a political, dialogical and ideological instance, as well as some pieces of research that support the potential of discourse genres for teaching. The corpus of analysis contains two English language lesson plans aimed at working with the written axis in elementary education. Our interpretative analysis of the cut corpus evidence that, although the plans include a proposal for working with texts, with attention to the development of the thematic content, textual production is still limited to the exploration of certain rigid characteristics of textual typology and to grammatical aspects.

Keywords: English language lesson plans; Aspects of textual production; Revista Nova Escola. 


\section{Notas}

1 Cerca de três milhões de visitantes por mês e vinte mil assinantes das revistas digital e impressa. Disponivel em: https://novaescola. org.br/parcerias-institucional.

3 P10 - https://novaescola.org.br/plano-deaula/2455/estrategias-de-escrita-construcao-da-persuasao; P15 - https://novaescola.org. br/plano-de-aula/2870/praticas-de-escrita.

4 É importante considerar que essas duas instituições têm desempenhado uma influência no contexto educacional brasileiro. A FL, por exemplo, esteve à frente de discussões sobre o texto da BNCC, e a Nova Escola atua como formadora e propagadora de conteúdos educacionais para professores, há mais de trinta anos, conforme sinaliza o próprio site: https:// doacao.novaescola.org.br/.

5 https://novaescola.org.br/plano-de-aula/1833/ argumentos-persuasivos-para-um-texto-publicitario

6 "Observe nos marcadores que podemos ver neste parágrafo (contudo, apesar de, porém/ mas) estes são caminhos para conectar ideias. Que tipo de ideias eles conectam?"

7 "zero condicional"

8 "segunda condicional".

9 "A fotorreportagem é um gênero jornalístico sem definições sedimentadas. Ela nasce na Alemanha na década de 1920 e se expande pelo mundo com a ascensão do regime nazista, em 1933. Seu local de publicação eram as revistas ilustradas, onde texto escrito e imagem se complementavam" (AGOSTINETI, 2010).

10 To write photo stories about our obligations and needs as citizens to create a peaceful Society.

\section{Referências}

AGOSTINETI, K. Fotorreportagem: a apropriação imagética da narrativa jornalística. In: CONGRESSO BRASILEIRO DE CIÊNCIAS DA COMUNICAÇÃO, 23, 2010, Caxias do Sul. Anais... Caxias do Sul, 2010, p. 1-14.

ALVES, W. M.; BESSA, J. C. R. Orientações para escrita da redação do Enem em vídeos do Youtube. Hipertextus Revista Digital, v. 19, p. 1-23, 2018.
AMORIM, M. As ciências humanas e sua especificidade discursiva. In: RODRIGUES, R. H.; PEREIRA, R. A. (org.). Estudos dialógicos da linguagem e pesquisas em linguística aplicada. São Carlos: Pedro \& João Editores, 2016. p. 17-45.

ANTUNES, I. Aula de Português: encontros \& interações. São Paulo: Parábola Editorial, 2003.

ARAÚJO, M.A.F.; FIGUEIREDO, F. J.Q. Interação e colaboração no processo de escrita e reescrita de textos em língua inglesa. Revista Desempenho, n. 24, v.1, 2015.

AZZARI, E. F. EFL collaborative writing: text production and online resources. Diálogo da Letras, v. 8, n. 1, p. 52-65, 5 abr. 2019.

BAKHTIN, M. Estética da criação verbal. 4. ed. Tradução de Paulo Bezerra. São Paulo: Martins Fontes, 2003.

BAKHTIN, M. [1895-1975]. Problemas da poética de Dostoiévski. 5. ed. Rio de Janeiro: Forense Universitária, 2015.

BAKHTIN, M. Os gêneros do discurso. Tradução de Paulo Bezerra. São Paulo: Editora $34,2016$.

BEATO-CANATO, A. P. M.; CRISTOVÃO, V. L. L. Cartas para penpal: descrição do contexto de produção e da infra-estrutura global de textos produzidos por estudantes brasileiros, norte-americanos e eslovacos. In: CRISTOVÃO, V. L. L. (org.). Modelos didáticos de gênero: uma abordagem para o ensino de língua estrangeira. Londrina, UEL, 2007, p. 121-132.

BESSA, J. C. R.; BERNARDINO, R. A. S. Equívocos em torno da escrita: o caso das dicas de produção de textos em vídeos do YouTube. Domínios de Lingu@gem, v. 11, p. 174, 2016.

BESSA, J. C. R. O lugar da leitura em orientações sobre produção de textos científicos: uma análise de sites e blogs educativos. In: GRAZIOLI, F. T.; SILVA, F. V. da (org.). Leituras sobre a leitura: ponderações transversais 
nos estudos da linguagem. Campinas, SP, Pontes Editores, 2019. p. 101-121.

BESSA, J. C. R. An analysis of guidelines on revision and rewriting of scientific texts in the digital universe. Educação e pesquisa, v. 46, p. 1-17, 2020.

BEZERRA, B. G. Gêneros no contexto brasileiro: questões [meta]teóricas e conceituais. São Paulo, Parábola Editorial, 2017.

BRASIL. Ministério da Educação. Base Nacional Comum Curricular - BNCC $3^{\text {a }}$ versão. Brasília, MEC, 2017.

BRITISH COUNCIL. Seis aspectos para a revisão da $3^{\underline{a}}$ versão da BNCC: componente língua inglesa. Nov./2017. Disponível em: https://educacaointegral.org.br/reportagens/o-lugar-do-ingles-na-base-nacional-comum-curricular-bncc/. Acesso em: 28 dz., 2018.

CAMPOS, A. G.; CRISTOVÃO, V. L. L. O gênero entrevista oral: subsídio para o ensino de língua inglesa. In: CRISTOVÃO, V. L. L. (org.). Modelos didáticos de gênero: uma abordagem para o ensino de língua estrangeira. Londrina, UEL, 2007. p. 139-172.

COSCARELLI, C. V. Navegar e ler na rota do aprender. In: COSCARELLI, C. V. (org.). Tecnologias para aprender. São Paulo: Parábola Editorial, 2016. p. 61-80.

COX, M. I. P.; ASSIS-PETERSON, A. A de. $\mathrm{O}$ professor de inglês: entre a alienação e a emancipação. Linguagem \& Ensino, v. 4, n. 1, p. 11-36, 2001.

CRISTOVÃO, V. L. L. [et al.]. Uma proposta de planejamento de ensino de língua inglesa em torno de gêneros textuais. Letras, Santa Maria, v. 20, n. 40, p. 191-215, jan./jun. 2010.

CURY, C. R. J.; REIS, M.; ZANARDI, T. A. C. Base Nacional Comum Curricular: dilemas e perspectivas. São Paulo, Cortez Editora, 2018.

DANTAS, S. G. M.; LIMA, S. DE C. A escrita colaborativa no Google Docs: uma proposta de ensino do gênero textual factual recount no ensino técnico de nível médio integrado.
Diálogo da Letras, v. 8, n. 3, p. 157-176, 20 dez. 2019.

DOLZ, J.; NOVERRAZ, M.; SCHNEUWLY, B. Seqüências didáticas para o oral e a escrita: apresentação de um procedimento. In: SCHNEUWLY, B.; DOLZ, J. (org.). Gêneros orais e escritos na escola. Tradução de Roxane Rojo e Glaís Sales Cordeiro. Campinas, SP: Mercado das Letras, 2004, p. 95-128.

DONATO, M. S. R.; RAJAGOPALAN, K. A aplicabilidade de textos autênticos no ensino-aprendizagem da língua inglesa: uma abordagem crítica-reflexiva no contexto público de ensino no Brasil. Revista Magistro, v. 1, n. 15, p. 175-190, 2017.

FARACO, C. A. Linguagem e diálogo: as ideias linguísticas do círculo de Bakhtin. Curitiba: Parábola Editorial, 2009.

FORTES, L. A representação do inglês/língua estrangeira como "matéria escolar" e alguns de seus efeitos nas práticas pedagógicas. Diálogo das Letras, v. 3, n. 1, p. 27-49, 2014.

GERALDI, J. W. Passando em revista ideias sobre o ensino de língua portuguesa: uma entrevista com João Wanderley Geraldi. Entrevista realizada por Lívia Suassuna e Rosângela Alves dos Santos Bernardino. Diálogo das Letras, v. 6, n. 1, p. 490-496, jan./jun. 2017.

GONÇALVES, M.; TORRES; M. C. Agir verbal, representações e responsabilidade enunciativa em sítios web institucionais. D.E.L.T.A, v. 33, n. 2, p. 519-541, 2017.

HACKMAN, H. W. Five essential components for social justice education. Equity \& Excellence in Education, v. 38, p. 103-109, 2005.

LIBERALI, F. Creative Chain in the Process of Becoming a Totality. Bakhtiniana, São Paulo, v. 1, n. 2, p. 100-124, 2. sem. 2009.

LIBERALI, F. C. Entrevista com Fernanda Coelho Liberali. Entrevista concedida às professoras Inés Kayon de Miller e Isabel 
Cristina Rangel Bezerra. Soletras, n. 35, p. 16-27, 2018.

MACEDO, E. Base Nacional Curricular Comum: novas formas de sociabilidade produzindo sentidos para educação. Revista e-curriculum, v. 12 , n. 3, p.1530-1555, out./ dez. 2014.

MACHADO, A. R. A perspectiva interacionista sociodiscursiva de Bronckart. In: MEURER, J. L.; BONINI, A.; MOTTA-ROTH, D. (org.). Gêneros: teorias, métodos, debates. São Paulo: Parábola Editorial, 2005.

MARCUSCHI, L. A. Produção textual, análise de gêneros e compreensão. São Paulo, Parábola, 2008.

MENDONÇA, M. C. A produção textual na esfera escolar: considerações sobre a "escrita como trabalho". Diálogo das Letras, v. 8, n. 1, p. 3-15, jan./abr. 2019.

MENDONÇA, M. R. S. Análise linguística: refletindo sobre o que há de especial nos gêneros. SANTOS, C. F.; MENDONÇA, M. R. S.; CAVALCANTI, M. C. B. (org.). Diversidade textual: os gêneros na sala de aula. Belo Horizonte, Autêntica, 2007. p. 73-88.

PAIVA, V. L. M. de O. Ensino de língua inglesa no ensino médio: teoria e prática. São Paulo, Edições SM, 2012.

PASQUIER, A.; DOLZ, J. Um decálogo para ensinar a escrever. Cultura y Educación, 2: 31-41. Madrid: Infância y aprendizaje. Tradução de R. H. R. Rojo. Circulação restrita, 1996

PONTARA, C.; CRISTOVÃO, V. L. L. Gramática/análise linguística no ensino de inglês (língua estrangeira) por meio de sequência didática: uma análise parcial. D.E.L.T.A., v. 33, n. 3, p. 873-909, 2017.

RIBAS, F. C. Base Nacional Comum Curricular e o ensino de língua inglesa: refletindo sobre cidadania, diversidade e criticidade à luz do Letramento Crítico. Domínios de Linguagem, v. 12, n. 3, p. 1785-1824, 2018.

RIBEIRO, A. E. Que futuros redesenhamos? Uma releitura do manifesto da Pedagogia dos Multiletramentos e seus ecos no Brasil para o século XXI. Diálogo das Letras, v. 9, p. 1-19, e02011, 2020.

ROCHA, C. H. A língua inglesa no ensino fundamental I público: diálogos com Bakhtin por uma formação plurilíngue. Trabalhos em Linguística Aplicada, v. 48, n. 2, p. 247-274, 2009.

ROCHA, C. H.; MACIEL, R. F. Ensino de língua estrangeira como prática translíngue: articulações com teorizações bakhtinianas. D.E.L.T.A., v. 31, n. 2, p. 411-445, 2015.

ROJO, R. H. R. Pedagogia dos multiletramentos. In: Multiletramentos na escola. Rojo. R.; MOURA, E. (org.). São Paulo: Parábola Editorial, 2012, p. 11-31.

ROJO, R.; BARBOSA, J. Hipermodernidade, multiletramentos e gêneros discursivos. São Paulo: Parábola Editorial, 2015.

ROTTAVA, L. Concepções de leitura e de escrita: um contraponto entre professores em formação de português, inglês e espanhol. In: ROTTAVA, L.; LIMA, M. S. (org.). Linguística aplicada: relacionando teoria e prática no ensino de línguas. Ijuí: Ed. UNIJUÍ, 2004. p. 111-138.

SANTOS, K. M., COSTA, C. J. S. A. Tecnologias digitais e ensino de inglês: uma proposta de escrita colaborativa e produção de vídeo. Observatório, v. 5, n. 6, p. 547-577, 2019.

SCHERER, A. S.; MOTTA-ROTH, D. Contribuições da análise crítica de gênero para a promoção de letramentos em inglês como língua adicional. In: TOLDO, C.; STURM, L. (org.). Letramento: práticas de leitura e escrita. Campinas, SP, Pontes, 2015, p.79-106.

SOARES, D. A. A revisão colaborativa e a produção textual em língua inglesa: o ponto de vista do aprendiz. Cadernos do $I L$, Porto Alegre, n. 36, jun. 2008.

SZUNDY, P. T. C. Educação como ato responsável: a formação de professores de linguagens à luz da filosofia da linguagem do círculo de Bakhtin. Trabalhos em Linguística Aplicada, Campinas, v. 53, n. 1, p. 13-32, 2014. 
ZACHARIAS, V. R. C. Letramento digital: desafios e possibilidades para o ensino. In: COSCARELLI, C. V. (org.). Tecnologias para aprender. São Paulo: Parábola Editorial, 2016. p. 15-29.

ZOZZOLI, R. M. D. Produção e autonomia relativa na aprendizagem de línguas. In: LEFFA, V. J. (org.). Pesquisa em linguística aplicada: temas e métodos. Pelotas: Educat, 2006. p. 105-143.

ZOZZOLI, R. M. D. A noção de compreensão responsiva ativa no ensino e na aprendizagem. Bakhtiniana, São Paulo, v. 7, n. 1, p. 253-269, Jan./Jun. 2012. 